\title{
CENTRO DIA PARA IDOSOS
}

Jéssica Telles Zanateli, Maria Alessandra Bacaro Boscoli

Arquitetura e Urbanismo - UNOESTE. E-mail: jessicazanateli@yahoo.com.br

\section{RESUMO}

O aumento da expectativa de vida e a redução da taxa de natalidade contribuirão para que a população, no futuro, seja de maioria idosa. A terceira idade possui aspectos que são contrários aos parâmetros de produtividade estabelecidos pela sociedade, o que leva à marginalização e incompreensão do idoso pela maioria das pessoas. No entanto, não se pode ignorar a grande demanda de serviços voltados para idosos. Eles precisam, principalmente, de dedicação de tempo e de carinho, mas nem todos os familiares podem oferecer isto. Por esta questão, faz-se necessária a criação de espaços que promovam atividades estimulantes para o corpo e a mente destas pessoas e que provocam bem-estar. Os Centros Dia para Idosos têm essa finalidade, ao passo que não afastam e até reforçam o contato com a família, ao contrário dos chamados asilos.

Palavras-chave: IDOSOS, MARGINALIZAÇÃO, CENTRO DIA PARA IDOSOS, ATIVIDADES, QUALIDADE DE VIDA.

\section{INTRODUÇÃO E OBJETIVO}

A arquitetura sempre acompanhou as características da sociedade. Ela pode ser definida como a condição humana inserida na construção. Sua função é atender da melhor maneira possível as diferentes necessidades e os anseios de diferentes pessoas. Sendo assim, pode-se dizer que ela se torna ineficaz ao oferecer a mesma solução para diferentes questões. Quanto aos espaços destinados aos idosos, por exemplo, muitas vezes não foram planejados de maneira adequada.

De acordo com os dados do IBGE (Instituto Brasileiro de Geografia e Estatística), o mundo está envelhecendo. Acredita-se que até 2050, a população mundial em sua maioria será idosa. O envelhecimento da população é resultado do aumento da expectativa de vida, que por sua vez se deve aos avanços na área da saúde e ao mesmo tempo à redução de natalidade (COBO $\mathrm{E}$ CAMARANO, 2012). O que mais vem preocupando é o fato de que ainda não se sabe lidar corretamente com o envelhecimento e com quem envelhece. O idoso está na margem da sociedade porque parece não se encaixar nos padrões sociais do que é útil e valoroso (SANTOS, 2009).

Com o passar dos anos, o idoso pode se tornar semi-dependente e precisar de mais do que apoio financeiro e psicológico. Em alguns casos, muitas famílias recorrem a um cuidador particular. Infelizmente, existem muitos casos de agressão ao idoso por parte destes profissionais, 
dentro da própria casa ou em instituições de permanência prolongada voltada para a terceira idade. Os chamados "asilos", às vezes, acabam prejudicando o idoso pelo distanciamento da família e pela falta de fiscalização que lá existe. Esses locais acabam se transformando em simples "depósitos de pessoas improdutivas" que necessitam de cuidados.

O objetivo deste trabalho é expor a atual situação da terceira idade e também a necessidade de opções na área de prestação de serviços para esta faixa etária, principalmente pessoas cujos familiares não possam pagar pelo serviço, diminuindo as chances de ocorrerem situações de maus tratos ou descaso, diminuindo a o risco de acidentes domésticos ao ficarem sozinhos, possibilitando aos idosos, continuarem ativos e compartilhar, participando de um processo de inserção na comunidade. Espaços que desempenhem tal função promoveriam o não isolamento da família e a construção de um indivíduo de estima elevada, levando-o a uma condição de saúde superior observando-se que seu emocional estaria mais equilibrado e a garantia de dignidade necessária e justa a quem anteriormente deu sua parcela de contribuição para construção da sociedade em que vivemos.

\section{METODOLOGIA}

A escolha do tema se deu devido à observação das necessidades da sociedade e a constatação do novo perfil da mesma, considerando o novo modelo de relações familiares, os papéis de cada ente familiar e os que eles desempenham no meio civil. Percebendo a carência de serviços para maiores de sessenta anos e o aumento da população de terceira idade, o projeto se tornou uma necessidade para melhoria da qualidade de vida de todos os cidadãos. A elaboração do presente trabalho se iniciou com a consulta de livros e artigos da internet sobre a relação dos idosos com a sociedade. Foram visitados locais que serviram como referências de instituições e projetos que cuidam de idosos, observando a funcionalidade e precariedade dos ambientes, e assim formular um programa de necessidades.]

\section{DISCUSSÃO}

Segundo Salvador (2009, apud SANTOS, 2004), os espaços são palcos para as atividades humanas. Como tal, precisam estar adequados às diferentes ações e pessoas. Os ambientes residenciais, de trabalho e públicos são projetados em massa de maneira a agradar e atender a maioria, mas às vezes são esquecidas as minorias que mais precisam de atenção. 
O envelhecimento é algo de difícil adaptação tanto para família quanto para o idoso. Ele sofre com a perda de auto estima, fica apático e angustiado devido ao aparecimento de doenças crônicas e mudanças de aparências, além das perdas familiares, dificuldades financeiras e ausência de um papel dentro da sociedade capitalista. Para cuidar disto é preciso que o idoso tenha o apoio da família para se sustentar e perceber que ele tem o seu valor. Junto a isso, ele irá perceber que só porque está em uma idade avançada que ele tem que deixar de fazer o que gosta e que sua vida social não tem que ser deixada de lado. Participar de grupos de terceira idade é um passo para a sua reinserção na sociedade, diz Oliveira', Fernandes e Carvalho (2011).

A população de idosos geralmente demanda melhorias na educação, segurança, cultura, trabalho, saúde e previdência social. Quando esses direitos essenciais passam a não ser respeitados, é necessária a intervenção de políticas públicas por parte do governo (OLIVEIRA, 2009). Camarano (apud OLIVEIRA, 2009) aponta que se as práticas não forem contínuas e não receberem investimentos, sua contribuição para maior expectativa de vida perderia o sentido. Segundo Oliveira (2009), estas atitudes visam principalmente que os próprios idosos se deem ao respeito e enxerguem a sua participação e importância na sociedade. Isto os fará serem mais ativos, confiantes e felizes. A parte legislativa das políticas públicas para o idoso consiste principalmente no Estatuto do Idoso que foi aprovado em setembro de 2003, após seis anos de tramitação e passou a ser vigente no primeiro dia de janeiro de 2004 (SOUZA). Souza relata que nele foram estipuladas normas de proteção e melhoria da qualidade de vida do idoso estabelecendo procedimentos legais para isto. Nele estão descritos os tipos de crimes contra idosos e as respectivas punições, a variação de valores de planos de saúde de acordo com a idade, o dever de conceder medicamentos por parte do poder público, atendimentos preferenciais, os descontos em diversas atividades culturais, de lazer, passagem gratuita no transporte público e descontos nas passagens interestaduais.

Dumazedier (apud TEIXEIRA, 2007, p. 173) considera o lazer associado a um comportamento que pode ser encontrado em qualquer atividade que cause satisfação, distração, entretenimento e capaz de aliviar o desgaste físico-mental produzido pelo cotidiano. Há também o ponto de vista que considera o lazer não apenas uma liberação do trabalho, mas inclusive das obrigações rotineiras, sociais, familiares ou políticas. A integração, valorização social e resocialização da terceira idade acontecem por iniciativas filantrópicas de empresários, por exemplo, - SESC e das Universidades Abertas da Terceira Idade. Estes levam entretenimento e conhecimento para idosos não institucionalizados (TEIXEIRA, 2007). 


\section{REFERÊNCIAS}

As construções existentes têm uma referência, arquitetônica ou não. Tudo que se pensa e cria provém, mesmo que uma parcela pequena, de algo que foi visto ou vivenciado. As experiências podem ser as mesmas para alguns, mas cada um irá interpretá-las de uma forma diferente. No caso do Centro Dia para Idosos, as referências despertam a atenção quanto ao programa de necessidades, possibilidades e práticas inviáveis para atender a função com qualidade. As visitas forneceram o conhecimento de como programas com idosos funcionam e o que as instalações deles têm de bom ou que pode ser melhorado nelas.

O Centro Dia para Idosos fica em um bairro afastado do centro na cidade de Votuporanga, noroeste do estado de São Paulo. A iniciativa e verba para construção da instituição veio do Governo do Estado, mas a mantenedora é a Prefeitura Municipal. O local se disponibiliza a atender idosos que precisam de atenção especial cujas famílias não podem pagar um cuidador particular e ao mesmo tempo tem que trabalhar para prover recursos a todos os seus dependentes. Para atender a demanda e priorizar quem de fato não tem condições manter um profissional especializado, existe uma assistente social fazendo uma triagem. No quadro de profissionais estão fisioterapeutas, enfermeiras, educador físico, assistente social e psicóloga, além de auxiliares de limpeza e de cozinha. As atividades desenvolvidas incluem artesanatos, convívio e conversas na sala de televisão e estar, caminhadas (sem regularidade), horário de descanso e exercícios leves acompanhados por profissionais tanto da área da fisioterapia quanto da educação física. As famílias mandam os pertences dos idosos diariamente para que eles usem as próprias roupas e utensílios de higiene, além de medicações de uso interno ou externo. O Centro oferece reuniões e dias de interação de todos os idosos e suas famílias, trocando experiências e demonstrando a real importância que seu parente tem. É relatada a melhora da qualidade de vida das pessoas e dos que os cercam depois que elas participam da rotina do estabelecimento.

O Centro de Referência da Terceira Idade "Feliz Idade" trabalha com prevenção, o Centro de Referência da Feliz Idade fica na Rua Ribeiro de Barros, próximo à Avenida Washington Luiz, região central de Presidente Prudente. O projeto é mantido pela Prefeitura Municipal e funciona a pouco menos de três anos. Nele são propostas aulas de informática, academia com acompanhamento de fisioterapeuta perante apresentação de atestado médico permitindo a prática, eventos que visam à interação entre os idosos e até a consolidação de laços afetivos. 


\section{CONCLUSÃO}

O envelhecimento, apesar de fazer parte da vida, ainda não é bem compreendido. Isso se reflete na arquitetura quanto ao planejamento de espaços não adaptados para as necessidades do idoso, e sim pensados para a maioria. Entretanto, o número de pessoas velhas vai ser a maioria do futuro. Com a crescente demanda, são exigidos serviços voltados para esta faixa etária. As situações de semi-dependência seriam atendidas pelo Centro dia para o Idoso e este cuidaria dos idosos enquanto seus familiares desempenham suas funções. Simultaneamente a isso, se trabalharia com prevenção de doenças e estímulos para a melhora da qualidade de vida.

\section{REFERÊNCIAS BIBLIOGRÁFICAS}

CAMARANO, Ana Amélia; COBO, Bárbara. In: Em 50 anos, percentual de idosos mais que dobra no Brasil. Disponível em:<http://g1.globo.com/brasil/noticia/ 2012/04/em-50-anos-percentualde-idosos-mais-que-dobra-no-brasil.html>. Acesso em: 21 nov. 2012.

IBGE $^{1}$ (Instituto Brasileiro de Geografia e Estatística). Em 50 anos, percentual de idosos mais que dobra no Brasil. Disponível em: <http://g1.globo.com/ brasil/noticia/ 2012/04/em-50-anospercentual-de-idosos-mais-que-dobra-no-brasil.html>. Acesso em 21 nov. 2012.

MAGALHÃES, Maria Lúcia; ORTEGA, Jakeline Margaret de Queiroz. Normas e Padrões para Apresentação de Trabalhos Científicos da Unoeste. 2.ed. Presidente Prudente: Universidade do Oeste Paulista, 2011.

OLIVEIRA, Rita de Cássia da Silva. Políticas Públicas, Educação e a Pesquisa sobre o Idoso no Brasil: Diferentes Abordagens da Temática nas Teses e Dissertações (de 2000 a 2009). IX ANPED SUL, 2012.2 Disponível em: <http://www.ucs.br/etc/conferencias/index.php/anpedsul/9anpedsul/paper/viewFile/1845/24>. Acesso em: 21 mar. 2013.

SALVADOR, Diego Salomão Candido de Oliveira. O Território Usado e o Uso Atual do Território do Agreste Potiguar. Salvador: Universidade Federal do Rio Grande do Norte, 2009. (Dissertação de Mestrado). Disponível em: <http://www.google.com.br/url?sa=t\&rct=j\&q=0s\%20espa\%C3\%A7os\%20s\%C3\%A30\%20palcos\%2 Opara\%20as\%20atividades\%20humanas\&source=web\&cd=2\&cad=rja\&sqi=2\&ved=0CDEQFjAB\&url =http\%3A\%2F\%2Fwww2.ifrn.edu.br\%2Fojs\%2Findex.php\%2FHOLOS\%2Farticle\%2Fdownload\%2F2 19\%2F196\&ei=4FCVUZOCNOvA4AOr9oH4Cg\&usg=AFQjCNHAOjvc3hOtVFnBBAAQzOcHo0xJgA\&bv $\underline{m=b v .46471029, d . d m g>. ~ A c e s s o ~ e m: ~} 16$ mai. 2013.

SANTOS, Acácia Aparecida Angeli dos. Envelhecimento e Subjetividade: desafios para uma cultura de compromisso social.1.ed. São Paulo: Conselho Federal de Psicologia, 2009.

SOUZA; Samuel Rodrigues de. 0 idoso na família e na sociedade. Disponível em: <http://www.montesiao.pro.br/estudos/familia/3idade/idosofamilia sociedade.html>. Acesso em: 14 abr. 2013. 
Encontro de Ensino, Pesquisa e Extensão, Presidente Prudente, 21 a 24 de outubro, 2013

TEIXEIRA, Solange Maria. Lazer e tempo livre na "terceira idade": potencialidades e limites no trabalho social com idosos. Disponível em: $<$ http://www.google.com.br/url?sa=t\&rct=j\&q=lazer\%20na\%20terceira\%20idade\&source=web\&c $\mathrm{d}=9 \& \mathrm{cad}=$ rja\&ved=0CHMQFjAI\&url=http\%3A\%2F\%2Frevistas.pucsp.br\%2Findex.php\%2Fkairos\%2F article\%2Fdownload\%2F2597\%2F1651\&ei=uGCRUamdOoW54AOwsYHIAw\&usg=AFQjCNG0CNA5S c5bl-fvWHIHkipRa-frcQ>. Acesso em: 10 mai. 2013. 